\title{
Title: Time-of-day matters - pronounced regional morning-to-evening effects in structural brain metrics
}

\author{
Authors and affiliations \\ Michal Rafal Zareba ${ }^{1,2, *}$, Magdalena Fafrowicz ${ }^{3}$, Tadeusz Marek ${ }^{3}$, Ewa Beldzik ${ }^{3}$, Halszka \\ Oginska $^{3}$, Aleksandra Domagalik ${ }^{2, *}$ \\ ${ }^{1}$ Institute of Zoology and Biomedical Research, Faculty of Biology, Jagiellonian University, \\ Kraków, Poland \\ ${ }^{2}$ Brain Imaging Core Facility, Malopolska Centre of Biotechnology, Jagiellonian University, \\ Kraków, Poland \\ 3 Department of Cognitive Neuroscience and Neuroergonomics, Institute of Applied \\ Psychology, Jagiellonian University, Kraków, Poland
}

* corresponding authors: michal.rafal.zareba@gmail.com (M.R.Z.), aleksandra.domagalik@uj.edu.pl (A.D.)

\begin{abstract}
In recent decades magnetic resonance imaging (MRI) has established itself as the golden standard for studying human brain structure in health and disease. As a result, it has become increasingly more important to identify factors that may influence study outcomes and contribute to misleading conclusions. With the regional time-of-day (TOD) differences in structural brain metrics utterly neglected and several studies reporting inconsistent TOD changes on the global brain level, this work set out to investigate this phenomenon with voxel-based (VBM) and surface-based morphometry (SBM) using the largest longitudinal dataset to date $(\mathrm{N}=77)$. VBM revealed ubiquitous and often bilaterally symmetric differences in local grey and white matter volume across multiple cortical and subcortical brain regions. The impact of TOD on regional SBM indices was less pronounced than for VBM, and no significant effects were observed for the global volume- and surface-based anatomical metrics. Our findings likely reflect a combination of experience- and circadian-related processes, with the former possibly linked to memory formation. By showing that TOD has a prevalent effect on local anatomical brain metrics, our study underlines the need for this factor to be strictly controlled at the stage of experimental planning and data analysis.
\end{abstract}

\section{Keywords}

MRI; time-of-day; brain structure; voxel-based morphometry; surface-based morphometry 


\section{Highlights}

- No differences were found for global volume- and surface-based structural metrics

- Local grey and white matter volume showed widespread time-of-day variability

- Several brain regions exhibited surface-based changes between morning and evening

- Findings likely reflect a combination of experience- and circadian-related processes

\section{Introduction}

Recent decades have seen a dramatic rise in the use of magnetic resonance imaging (MRI) for studying the human brain structure and function in health and disease. Good contrast between the grey matter (GM), white matter (WM) and cerebrospinal fluid (CSF) along with the method's non-invasiveness and ability to measure brain activity have deemed it a superior choice for research purposes compared to computed tomography (CT) and positron emission tomography (PET). In particular, one of the most widely used anatomical techniques is T1-weighted morphometry. Its usefulness stems from a combination of short data acquisition time and fully automated image processing pipelines that provide researchers with a number of valuable metrics reflecting different aspects of brain anatomy. Among these, the most popular are voxel-based morphometry (VBM), which measures the relative volume of GM and WM in each voxel in the brain, as well as surface-based morphometry (SBM), which generates indices such as cortical thickness, sulcal depth and gyrification for all vertices in the cerebral cortex. In favour of these techniques, their utility has also been confirmed by several studies relating these derived parameters to histological data (Cardinale et al., 2014; Keifer et al., 2015; Suzuki et al., 2015; Asan et al., 2021).

As the involvement of MRI in brain research has become ubiquitous, more and more attention has been paid to variables that may influence study outcomes. It has been shown that structural MRI data can be affected by technical factors such as magnetic field strength, scanner hardware, pulse sequence used for data acquisition, as well as head tilt and location of the brain along the z-axis of the magnet (Han et al., 2006; Narayanan et al., 2020; Hedges et al., 2021). Recently, successful efforts have been made to increase the comparability of the data between the scanning sites through the means of data harmonisation (Radua et al., 2020). Nevertheless, a body of literature shows that other often neglected factors unrelated to the hardware, such as time-of-day (TOD) when the data was collected, may still strongly confound neuroimaging findings. Indeed, previous MRI studies have found widespread TOD-dependent differences in task-related brain activity, resting-state functional connectivity, as well as WM microstructure (Marek et al., 2010; Orban et al., 2020; Fafrowicz et al., 2019; Farahani et al., 2021; Thomas et al., 2018; Voldsbekk et al., 2020). Similarly, several works have reported TOD findings for 
global brain morphometric features, as well as VBM and SBM; nevertheless, inconsistencies are present in the literature.

Two longitudinal investigations have shown TOD-related decreases in total brain volume (Nakamura et al., 2015; Trefler et al., 2016). Additionally, the latter study reported decreases in the volumes of GM and WM, a reduction in cortical thickness and surface area, as well as CSF volume increase. The volumetric changes of CSF were negatively correlated with the differences in GM and WM volume. The work also reported no significant TOD variation in cortical curvature and sulcal depth. In contrast with these results, a larger cross-sectional investigation observed no association between brain volume and TOD (Book et al., 2021). While this discrepancy could be related to the differences in the experimental design with the two longitudinal works better suited to detect the effects of interest, additional evidence comes from several other studies. Karch et al. confirmed TOD-related GM and cerebral cortex volume decrease, however, found no such distinctions for WM volume (Karch et al., 2019). In a different investigation, Maclaren et al. reported a significant TOD increase in ventricular (CSF) volume only in one of three participants (Maclaren et al., 2014). Last but not least, Naranayan and colleagues showed that the TOD-related brain volume change was similar in magnitude to the variations from the daily scans performed at the same time of the day over a week (Naranayan et al., 2020). Additionally, the TOD effect was weaker than scan-reposition-rescan variability.

The work by Trefler et al. was also the first and the only one to investigate the TOD variability for VBM and SBM measures (Trefler et al., 2016). They reported VBM GM decreases in several areas within the frontal, temporal and parietal lobes, as well as in the cerebellum and caudate nucleus. The reductions in cortical thickness were present in frontal, temporal, parietal and occipital regions, with the first two lobes showing a greater extent of decrease. Interestingly, only one brain structure (temporal pole) was found to undergo TOD-related thickening. In contrast with these results, in a different investigation by Elvsåshagen and colleagues the prefrontal cortex was found to increase its thickness from morning to evening (Elvsåshagen et al., 2017).

Given the limited number of studies and the presence of inconsistencies in the literature, we aimed to investigate the TOD variation in structural brain data in an extended cohort $(\mathrm{N}=77)$ from earlier works showing widespread TOD variation in resting-state functional connectivity (Fafrowicz et al., 2019; Farahani et al., 2021). To the best of our knowledge, it is the largest dataset used to date in the context of the TOD effect in VBM and SBM. Firstly, we aimed to verify the earlier reports on the TOD variation in the global brain, GM, WM and CSF volumes, and a number of surface-based metrics, i.e. cortical thickness, sulcal depth and gyrification index. The second goal was to explore the vertex- and voxel-level effects for the aforementioned 
SBM indices, as well as GM and WM VBM. In this regard, we are the first study to investigate regional changes in sulcal depth, gyrification and WM volume in such a manner.

\section{Materials and methods}

\subsection{Participants}

77 volunteers were recruited for the study. All participants were right-handed, had normal or corrected to normal vision, no history of neurological and psychiatric disorders, and were drug-free. The following additional inclusion criteria were applied: age between 19 and 35 years, no shift work, not having been on a flight crossing more than two time zones within the past two months, declared regular daily schedule with no sleep debt (from 6 to 9 hours of sleep each night). The level of daytime sleepiness was controlled with Epworth Sleepiness Scale (ESS; Johns, 1991) and sleep quality with Pittsburgh Sleep Quality Index (PSQI; Buysse et al., 1989). The regularity of participants' sleep-wake schedule was checked for one week prior to MRI scanning using MotionWatch8 actigraphs (CamNtech Ltd.). After inspection of the MRI data, five participants were excluded from the study: three individuals due to unsatisfactory removal of meninges during the brain segmentation process and two participants due to being outliers in the daily changes of brain compartments volumes (exceeding 3 standard deviations (SD) for all compartments). Thus, the final sample consisted of 72 participants (45 females). The summary of the cohort's demographics and actigraphy-derived sleep characteristics is provided in Supplementary Material Table 1.

Each participant underwent two scanning sessions: one in the morning, and the other one in the evening, about 1 and 10 hours after awakening, respectively. The beginning of experimental sessions (morning and evening) was adjusted to the declared and objective (derived from actigraphic data) sleep-wake pattern of participants on a regular working day. The morning scans were acquired between 8:00 $\mathrm{AM}$ and 10:20 AM, whereas the evening scans were collected between 5:00 PM and 7:20 PM. The session order was counterbalanced across participants. Participants completed the study on one day (when the morning session was first) or on two consecutive days (when the evening session was first). On the night before the morning session participants slept in the rooms located in the same building as the MRI laboratory. They were only allowed to engage in non-strenuous activities during the experimental days. Participants abstained from alcohol $(48 \mathrm{~h})$ and caffeine $(24 \mathrm{~h})$ before the first session. Caffeine and alcohol were also banned during study days. The study was performed between November 2016 and January 2018 in the MR Laboratory, Malopolska Centre of Biotechnology, Jagiellonian University, Kraków, Poland. It was conducted under the Declaration of Helsinki and approved by the Ethics Committee for Biomedical Research at the Military Institute of Aviation Medicine (Warsaw, Poland; 26 February 2013) and the Research 
Ethics Committee of the Institute of Applied Psychology at Jagiellonian University (Kraków, Poland; 21 February 2017).

Circadian preference of the participants was assessed with the Chronotype Questionnaire (Oginska, 2011; Oginska et al., 2017) and controlled throughout all the analyses performed. In all of the analyses, there were no interactions between chronotype and TOD $(p>$ 0.05 ), and in the case of voxel- and vertex-level comparisons the brain areas under significant influence of one factor were different from those affected by the other one. The current dataset was a part of a larger investigation on the effects of chronotype on brain morphometric parameters, the results of which are described elsewhere (Zareba et al., 2021).

\subsection{Data acquisition}

MRI data was acquired using a 3T scanner (Magnetom Skyra, Siemens) equipped with a 64-channel head/neck coil. High-resolution, structural images were collected using a T1 MPRAGE sequence (176 sagittal slices; $1 \times 1 \times 1.1 \mathrm{~mm} 3$ voxel size; TR $=2300 \mathrm{~ms}$, TE $=2.98 \mathrm{~ms}$, flip angle $=9^{\circ}$, GRAPPA acceleration factor 2 ).

\subsection{Data analysis}

MRI data was processed with a longitudinal design in the Computational Anatomy Toolbox (CAT12; Gaser and Dahnkne, 2016) using volumetric and surface approaches. The volumetric stream consisted of VBM (Ashburner and Friston, 2000) analysis for GM and WM segments. The surface stream encompassed estimation of cortical thickness, sulcal depth and gyrification index for the cerebral cortex (Luders et al., 2006; Dahnke et al., 2013).

\subsection{Voxel-based morphometry}

The images underwent processing with the standard VBM pipeline. Firstly, each volume was segmented into GM, WM and CSF, which was followed by normalisation into the MNI152 space using diffeomorphic anatomical registration through exponentiated lie algebra (DARTEL). Such normalised GM and WM segments were subsequently modulated with the Jacobian determinant to account for the resulting signal intensity changes. The preprocessed GM and WM volumes were inspected visually to ensure satisfactory quality of the segmentation. Lastly, each of the segmented, normalised, and modulated images underwent smoothing with a 4-mm Gaussian filter.

The statistical analysis was performed separately for each tissue class using the $3 \mathrm{dLME}$ program (Chen et al., 2013) available in AFNI (Cox, 1996). Voxels with estimated mean study-wise volumes lower than 0.1 were excluded from the analyses to prevent the inclusion of non-brain data. The TOD effects were assessed using paired t-tests. Chronotype, sex, age and total intracranial volume (ICV) were controlled as covariates. Multiple comparison correction 
was achieved through cluster-level family-wise error rate correction (FWE; $p<0.05)$ following the initial voxel-level thresholding $\left(\mathrm{p}_{\text {uncorrected }}<0.001\right)$.

To compare the spatial characteristics of the observed GM and WM volumetric changes, the resulting morning-to-evening increases and decreases were binarised separately for each tissue class, resulting in 4 binary masks. Two additional masks were created: one for voxels showing simultaneous GM increases and WM decreases, the other one for voxels with the opposite pattern of differences. Subsequently, the voxels found to be simultaneously involved in the TOD effects for both tissue classes were excluded from the four original masks. In the final step, the six masks were added together with voxels belonging to each separate mask receiving a value from 1 to 6 . This enabled us to delineate all types of results.

\subsection{Surface-based morphometry}

The SBM stream was run after the volumetric steps were completed. Estimation of cortical thickness and reconstruction of the central surface was performed in one step using a projection-based thickness method (Dahnke et al., 2013), which allows handling of partial voluming, sulcal blurring, and sulcal asymmetries without explicit sulcus reconstruction. Following the initial surface reconstruction, topological defects were repaired and the surface was refined, creating the final central surface mesh (Yotter et al., 2011), which served as a basis for extracting folding patterns. The mesh was subsequently mapped onto Freesurfer's FsAverage template. In addition to cortical thickness maps, gyrification index and sulcal depth meshes were created.

Prior to statistical analysis, gyrification index and sulcal depth maps were smoothed with a Gaussian filter of $15 \mathrm{~mm}$, while the thickness meshes were smoothed with a $10 \mathrm{~mm}$ FWHM kernel. The analysis was performed in CAT12, separately for each surface parameter. The TOD effect was assessed with paired t-tests. Chronotype, sex and age were controlled in the form of covariates. Multiple comparison correction was performed with cluster-level FWE ( $p<$ $0.05)$ after initial vertex-wise thresholding ( $\left.\mathrm{p}_{\text {uncorrected }}<0.001\right)$.

In the case of spatial overlap between VBM GM and SBM TOD effects, raw values from the respective clusters were extracted for morning and evening sessions, and the TOD change was calculated (i.e. evening minus morning value). Subsequently, the TOD changes in the volumetric and surface parameters were correlated with each other using the cor.test function from $\mathrm{R}$ (version 4.0.3).

\subsection{Global anatomical metrics}

The global TOD effects (i.e. evening minus morning values) were calculated in $\mathrm{R}$ (version 4.0.3.) for each participant as a percentage change for several metrics: volumes of GM, $\mathrm{WM}$, brain (i.e. GM + WM) and CSF (as a percentage of ICV), as well as cortical thickness, 
sulcal depth and gyrification index (with the brain-average morning values for each participant serving as the reference point, i.e. 100\%). The volumetric data was based on the segmentation results, whereas the brain-wise means for the surface parameters stemmed from unsmoothed mesh data. In the next step, the distributions of the resulting values were checked for normality with the Shapiro-Wilk test. The TOD differences for WM volume $(\mathrm{p}=0.482)$, cortical thickness $(p=0.068)$ and sulcal depth $(p=0.964)$ were found to follow the Gaussian distribution, and thus the significance of these effects was assessed with paired t-tests (t.test). All other variables, i.e. GM, CSF, brain volume and gyrification index were not normally distributed $(\mathrm{p}<0.001)$, and thus the significance of TOD changes was assessed with a nonparametric Wilcoxon signed-rank test (wilcox.test).

Additionally, Spearman's correlations between TOD-related changes in GM, WM and CSF volumes were calculated with R's cor.test function. The correction for multiple comparisons was achieved with the Bonferroni's method (FWE).

\section{Results}

\subsection{TOD effects for global anatomical metrics}

No significant TOD effect was observed for any of the global volumetric and surface metrics (see Table 1 for more details). In turn, the correlational analysis revealed that TOD-related changes in GM volume were inversely correlated with the changes in CSF ( $\rho=$ -0.86; $\left.\mathrm{p}_{\text {FWE }}<0.001\right)$ and WM volumes $\left(\rho=-0.50 ; \mathrm{p}_{\text {FWE }}<0.001\right)$. No correlation between TOD differences in CSF and WM volumes was found $\left(\rho=0.08 ; \mathrm{p}_{\text {uncorrected }}=0.467\right)$. The distribution of the data is depicted in Figure 1. 
Table 1. Time-of-day (TOD) differences in the global anatomical metrics.

\begin{tabular}{|l|l|l|l|l|}
\hline Global anatomical metric & Mean $/$ Median $^{\mathrm{b}}$ & $\mathrm{SD}^{\mathrm{a}} / \mathrm{MAD}^{\mathrm{b}}$ & $\mathrm{T}$-stat & $\mathrm{p}_{\text {uncorrected }}$ \\
\hline $\begin{array}{l}\text { GM volume } \\
\text { relative to ICV [\%] }\end{array}$ & $0.10^{\mathrm{b}}$ & $0.74^{\mathrm{b}}$ & $\mathrm{n} / \mathrm{a}$ & 0.792 \\
\hline $\begin{array}{l}\text { WM volume } \\
\text { relative to ICV [\%] }\end{array}$ & $-0.08^{\mathrm{a}}$ & $0.38^{\mathrm{a}}$ & -1.825 & 0.072 \\
\hline $\begin{array}{l}\text { Brain volume } \\
\text { relative to ICV [\%] }\end{array}$ & $-0.10^{\mathrm{b}}$ & $0.74^{\mathrm{b}}$ & $\mathrm{n} / \mathrm{a}$ & 0.478 \\
\hline $\begin{array}{l}\text { CSF volume } \\
\text { relative to ICV [\%] }\end{array}$ & $0.10^{\mathrm{b}}$ & $0.74^{\mathrm{b}}$ & $\mathrm{n} / \mathrm{a}$ & 0.528 \\
\hline $\begin{array}{l}\text { Cortical thickness } \\
\text { relative to morning value [\%] }\end{array}$ & $0.10^{\mathrm{a}}$ & $0.95^{\mathrm{a}}$ & 0.943 & 0.348 \\
\hline $\begin{array}{l}\text { Sulcal depth } \\
\text { relative to morning value [\%] }\end{array}$ & $-0.15^{\mathrm{a}}$ & $0.86^{\mathrm{a}}$ & -1.522 & 0.132 \\
\hline $\begin{array}{l}\text { Gyrification index } \\
\text { relative to morning value [\%] }\end{array}$ & $-0.01^{\mathrm{b}}$ & $0.13^{\mathrm{b}}$ & $\mathrm{n} / \mathrm{a}$ & 0.558 \\
\hline
\end{tabular}

${ }^{a}$ Means and standard deviations (SDs) indicate the use of the paired t-test. ${ }^{b}$ Medians and median absolute deviations (MADs) indicate the use of the Wilcoxon test. Abbreviations: $\mathrm{GM}=$ grey matter; ICV = intracranial volume; $\mathrm{n} / \mathrm{a}=$ non-applicable; $\mathrm{WM}=$ white matter; $\mathrm{CSF}=$ cerebrospinal fluid. 
a. CSF vs. GM

$\rho=-0.86, p<0.001$

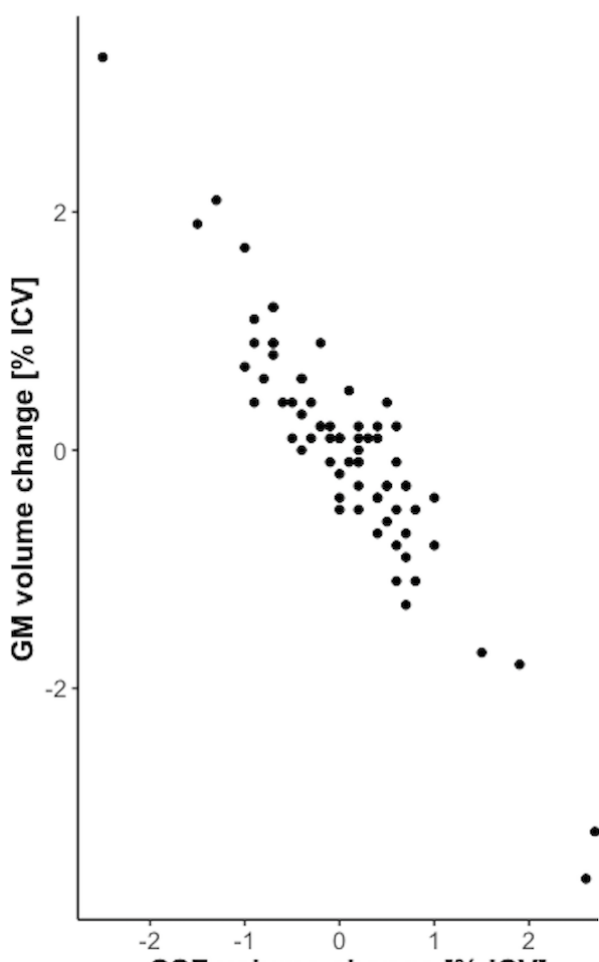

CSF volume change $[\% \mathrm{ICV}]$ b. CSF vs. WM

$\rho=0.08, p=0.467$

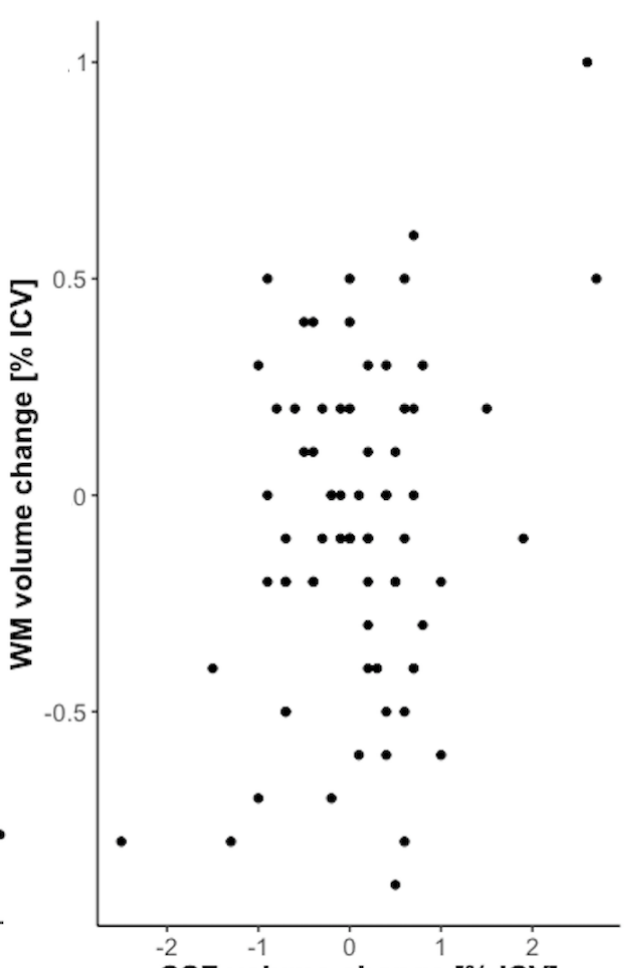

CSF volume change [\% ICV] c. WM vs. GM

$\rho=-0.50, p<0.001$

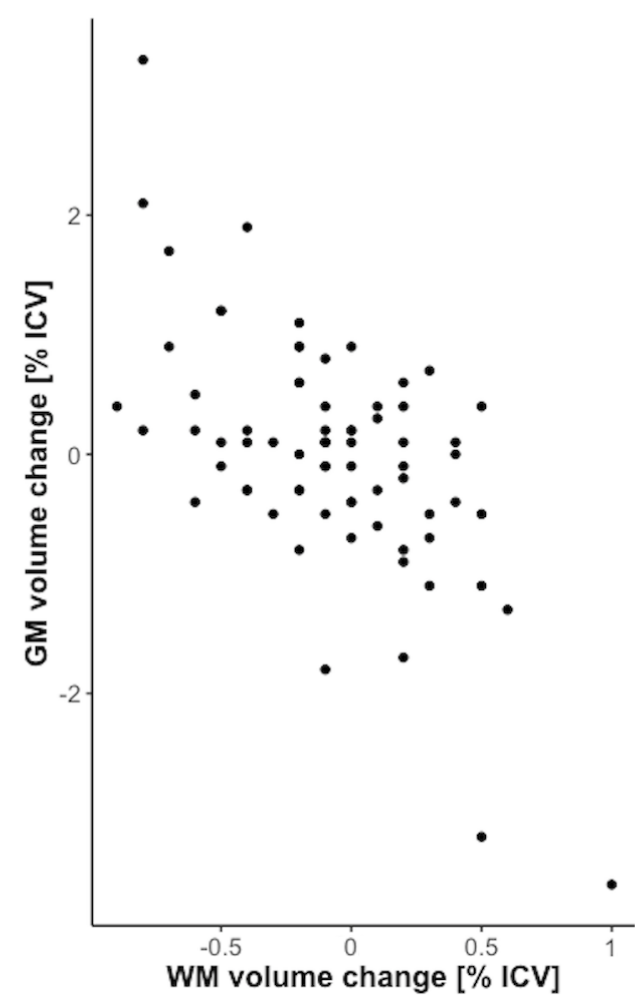

Figure 1. The distribution of the time-of-day (TOD) changes in the volume of grey matter (GM), white matter (WM) and cerebrospinal fluid (CSF). TOD-related differences in the GM volume were negatively correlated with variations in the CSF $\left(\rho=-0.86 ; \mathrm{p}_{\mathrm{FWE}}<0.001\right)$ and WM volumes $\left(\rho=-0.50 ; p_{\text {FWE }}<0.001\right)$. There was no monotonic relation between the changes in the CSF and WM volumes $\left(\rho=0.08 ; p_{\text {uncorrected }}=0.467\right)$. Abbreviations: $I C V=$ intracranial volume.

\subsection{TOD effects for VBM}

Evening scans were associated with greater GM volume in the bilateral orbitofrontal cortex, hippocampi, amygdalae, middle temporal gyri and parietal cortex, along with decreased GM concentration in bilateral nucleus accumbens and posterior cingulate cortex ( $\left.\mathrm{p}_{\mathrm{FWE}}<0.05\right)$. Furthermore, WM volume increase was observed in the anterior commissure and the bilateral fornices, whereas bilateral WM decreases were found in the orbitofrontal cortex, cingulate, as well as temporal and parietal lobes $\left(\mathrm{p}_{\mathrm{FWE}}<0.05\right)$. Apart from the symmetrical patterns described above, GM volume increases were also found in the right fusiform gyrus and cerebellar cortex, while decreased GM concentration was observed in the right caudate nucleus $\left(\mathrm{p}_{\mathrm{FWE}}<0.05\right)$. Both GM volume increases and decreases were found in distinct parts of the right inferior temporal gyrus $\left(\mathrm{p}_{\mathrm{FWE}}<0.05\right)$. Increased WM volume was observed in the right internal 
capsule, superior cerebellar peduncle and brainstem, while decreased WM concentration was found in several regions within the right frontal lobe $\left(\mathrm{p}_{\mathrm{FWE}}<0.05\right)$. The results are described in more detail in Table 2 and Figure 2.

Table 2. Time-of-day (TOD) differences in the voxel-based morphometry (VBM) ( $\left.\mathrm{p}_{\text {FWE }}<0.05\right)$.

\begin{tabular}{|c|c|c|c|c|c|}
\hline Tissue class & MNI & Voxels & Location & Directionality & t-stat \\
\hline \multicolumn{6}{|l|}{ Frontal lobe } \\
\hline GM & $8,49,-25$ & 428 & $\mathrm{R}$ orbitofrontal cortex & $\mathrm{E}>\mathrm{M}$ & 4.61 \\
\hline GM & $-9,35,-23$ & 156 & $\mathrm{~L}$ orbitofrontal cortex & $\mathrm{E}>\mathrm{M}$ & 5.60 \\
\hline GM & $-19,32,-15$ & 99 & $\mathrm{~L}$ orbitofrontal cortex & $\mathrm{E}>\mathrm{M}$ & 4.94 \\
\hline WM & $26,28,-11$ & 1098 & $\mathrm{R}$ orbitofrontal cortex & $\mathrm{M}>\mathrm{E}$ & 4.86 \\
\hline WM & $-19,41,-8$ & 423 & $\mathrm{~L}$ orbitofrontal cortex & $\mathrm{M}>\mathrm{E}$ & 5.23 \\
\hline WM & $-33,40,0$ & 103 & $\mathrm{~L}$ orbitofrontal cortex & $M>E$ & 4.70 \\
\hline WM & $-4,-4,45$ & 109 & L cingulate & $M>E$ & 5.10 \\
\hline WM & $6,-8,45$ & 179 & $\mathrm{R}$ cingulate & $M>E$ & 4.63 \\
\hline WM & $23,2,52$ & 328 & $\mathrm{R}$ frontal, sublobar & $M>E$ & 4.91 \\
\hline WM & $-22,-29,52$ & 295 & $\mathrm{R}$ frontal, sublobar & $\mathrm{M}>\mathrm{E}$ & 5.19 \\
\hline WM & $-18,2,52$ & 241 & $\mathrm{R}$ frontal, sublobar & $\mathrm{M}>\mathrm{E}$ & 4.90 \\
\hline WM & $48,-4,27$ & 233 & $\mathrm{R}$ frontal, subgyral and sublobar & $M>E$ & 5.60 \\
\hline WM & $27,-27,51$ & 204 & $\mathrm{R}$ frontal, sublobar & $M>E$ & 5.16 \\
\hline WM & $9,-23,51$ & 115 & $\mathrm{R}$ frontal, sublobar & $\mathrm{E}>\mathrm{M}$ & 4.65 \\
\hline \multicolumn{6}{|c|}{ Temporal lobe } \\
\hline GM & $-33,-5,-18$ & 296 & $\begin{array}{l}\text { L amygdala } \\
\text { L hippocampus }\end{array}$ & $\mathrm{E}>\mathrm{M}$ & 5.63 \\
\hline GM & $35,-8,-40$ & 253 & $\mathrm{R}$ fusiform gyrus & $\mathrm{E}>\mathrm{M}$ & 6.02 \\
\hline
\end{tabular}




\begin{tabular}{|c|c|c|l|c|c|}
\hline & & & $\begin{array}{l}\text { R hippocampus } \\
\text { R amygdala }\end{array}$ & \\
\hline GM & $55,-8,-18$ & 265 & R middle temporal gyrus & E $>$ M & 4.95 \\
\hline GM & $-58,2,-20$ & 148 & L middle temporal gyrus & E $>$ M & 5.24 \\
\hline GM & $54,-39,-34$ & 113 & R inferior temporal gyrus & M $>$ E & 4.76 \\
\hline GM & $52,-51,-24$ & 91 & R inferior temporal gyrus & E $>$ M & 4.40 \\
\hline WM & $35,-8,-40$ & 308 & R temporal, subgyral and sublobar & M $>$ E & 6.15 \\
\hline WM & $-33,-7,-18$ & 281 & L temporal, sublobar & M $>$ E & 6.85 \\
\hline
\end{tabular}

Parietal lobe

\begin{tabular}{|c|c|c|c|c|c|}
\hline GM & $2,-44,5$ & 217 & B posterior cingulate gyrus & $\mathrm{M}>\mathrm{E}$ & 4.56 \\
\hline GM & $23,-42,58$ & 150 & $\begin{array}{l}\text { R superior parietal lobe } \\
\text { R postcentral gyrus }\end{array}$ & $\mathrm{E}>\mathrm{M}$ & 4.57 \\
\hline GM & $38,-32,41$ & 127 & $\begin{array}{l}\mathrm{R} \text { superior parietal lobe } \\
\mathrm{R} \text { postcentral gyrus }\end{array}$ & $\mathrm{E}>\mathrm{M}$ & 6.75 \\
\hline GM & $-21,-66,42$ & 126 & L intraparietal sulcus & $\mathrm{E}>\mathrm{M}$ & 4.90 \\
\hline GM & $26,-53,63$ & 121 & $\mathrm{R}$ superior parietal lobe & $\mathrm{E}>\mathrm{M}$ & 4.88 \\
\hline WM & $-21,-40,54$ & 885 & L parietal, subgyral and sublobar & $\mathrm{M}>\mathrm{E}$ & 5.50 \\
\hline WM & $27,-36,44$ & 867 & R parietal, subgyral and sublobar & $\mathrm{M}>\mathrm{E}$ & 6.62 \\
\hline WM & $24,-52,60$ & 526 & R parietal, subgyral and sublobar & $\mathrm{M}>\mathrm{E}$ & 5.56 \\
\hline WM & $-25,-47,37$ & 203 & $\mathrm{R}$ parietal, sublobar & $\mathrm{M}>\mathrm{E}$ & 4.87 \\
\hline WM & $-48,-47,40$ & 280 & L parietal, sublobar & $\mathrm{M}>\mathrm{E}$ & 5.63 \\
\hline \multicolumn{6}{|c|}{ Subcortical areas and cerebellum } \\
\hline GM & $12,12,4$ & 310 & $\begin{array}{l}\mathrm{R} \text { caudate nucleus } \\
\mathrm{R} \text { nucleus accumbens }\end{array}$ & $\mathrm{M}>\mathrm{E}$ & 5.62 \\
\hline
\end{tabular}


bioRxiv preprint doi: https://doi.org/10.1101/2022.03.06.483163; this version posted March 7,2022 . The copyright holder for this preprint (which was not certified by peer review) is the author/funder, who has granted bioRxiv a license to display the preprint in perpetuity. It is made available under aCC-BY-ND 4.0 International license.

\begin{tabular}{|c|c|c|l|c|c|}
\hline GM & $-7,1,-14$ & 104 & L nucleus accumbens & M $>$ E & 4.47 \\
\hline GM & $18,-81,-53$ & 177 & R cerebellar lobule VIII & E > M & 4.27 \\
\hline GM & $54,-60,-45$ & 96 & $\begin{array}{l}\text { R cerebellar lobule VIIa crus I } \\
\text { R cerebellar lobule VIIa crus II }\end{array}$ & E > M & 4.52 \\
\hline WM & $12,10,2$ & 370 & $\begin{array}{l}\text { R internal capsule } \\
\text { Anterior commissure } \\
\text { B fornix }\end{array}$ & E M & 5.49 \\
\hline WM & $14,-30,-26$ & 109 & $\begin{array}{l}\text { R superior cerebellar peduncle } \\
\text { R brainstem }\end{array}$ & E $>M$ \\
\hline
\end{tabular}

Abbreviations: $\mathrm{R}=$ right; $\mathrm{L}=$ left; $\mathrm{GM}=$ grey matter; $\mathrm{WM}=$ white matter; $\mathrm{E}=$ evening; $\mathrm{M}=$ morning. 
bioRxiv preprint doi: https://doi.org/10.1101/2022.03.06.483163; this version posted March 7, 2022. The copyright holder for this preprint

(which was not certified by peer review) is the author/funder, who has granted bioRxiv a license to display the preprint in perpetuity. It is made available under aCC-BY-ND 4.0 International license.

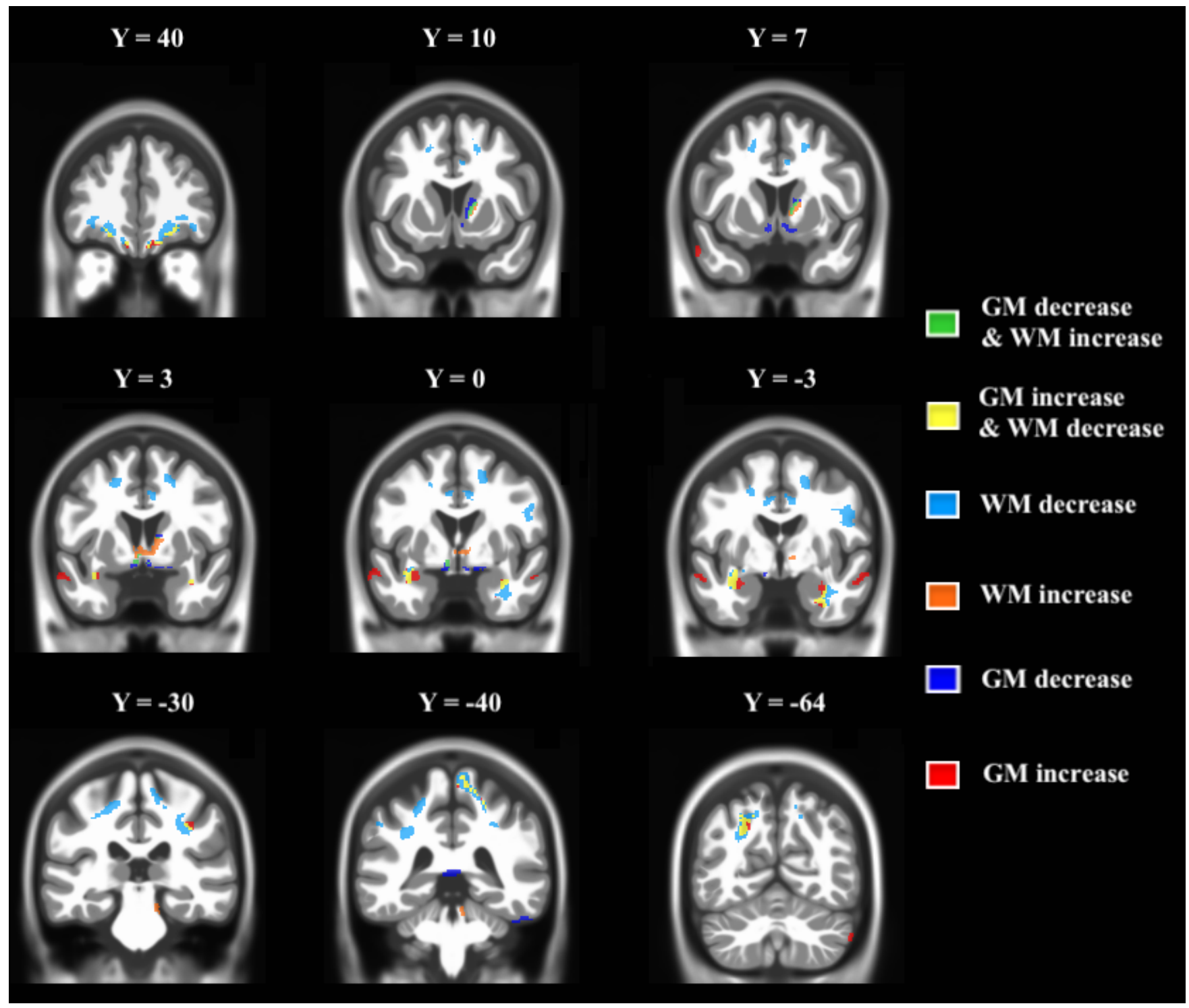

Figure 2. The time-of-day (TOD) effect on the voxel-based morphometry (VBM) across several brain regions $\left(\mathrm{p}_{\mathrm{FWE}}<0.05\right)$.

Comparing the spatial location of GM and WM volumetric changes revealed two characteristic patterns of morning-to-evening differences. GM volume increases, surrounded by voxels with simultaneous GM increase and WM decrease, followed by voxels with WM decrease were found in the following bilateral regions: the orbitofrontal cortex, hippocampi and amygdalae, as well as the parietal cortex. The opposite pattern, i.e. GM volume decrease - GM volume decrease and WM volume increase - WM volume increase, was observed in the bilateral nucleus accumbens and the right caudate nucleus. 
The sulcal depth in the right lateral occipital and inferior temporal cortex $\left(\mathrm{p}_{\mathrm{FWE}}=0.001\right)$ and the gyrification index in the right superior temporal cortex $\left(\mathrm{p}_{\mathrm{FWE}}=0.014\right)$ were found to increase from morning to evening. The opposite results were found for the gyrification index in the right precentral and postcentral gyri $\left(\mathrm{p}_{\mathrm{FWE}}=0.001\right)$ and thickness of the right paracentral lobule $\left(\mathrm{p}_{\mathrm{FWE}}=0.002\right)$. A trend level decrease in thickness was also observed for the right dorsomedial prefrontal cortex (DMPFC), including anterior cingulate and superior frontal gyri $\left(\mathrm{p}_{\mathrm{FWE}}=0.051\right)$. The results are shown in more detail in Table 3 and Figure 3.

Table 3. Regional time-of-day (TOD) differences in the cortical surface parameters.

\begin{tabular}{|c|c|c|l|c|c|c|}
\hline Measure & Coordinates & Vertices & \multicolumn{1}{|c|}{ Location } & Directionality & t-stat & $\begin{array}{c}\text { cluster-level } \\
\text { p value }\end{array}$ \\
\hline Depth & $47,-66,-8$ & 1163 & $\begin{array}{l}\text { R lateral occipital cortex } \\
\text { R inferior temporal gyrus }\end{array}$ & E > M & 4.30 & 0.001 \\
\hline Gyrification & $49,-24,-5$ & 397 & R superior temporal gyrus & $\mathrm{E}>\mathrm{M}$ & 4.51 & 0.014 \\
\hline Gyrification & $15,-32,60$ & 620 & $\begin{array}{l}\text { R precentral gyrus } \\
\text { R postcentral gyrus }\end{array}$ & $\mathrm{M}>\mathrm{E}$ & 4.81 & 0.001 \\
\hline Thickness & $5,-18,56$ & 523 & R paracentral lobule & $\mathrm{M}>\mathrm{E}$ & 4.03 & 0.002 \\
\hline Thickness & $9,52,8$ & 300 & R superior frontal gyrus & $\mathrm{M}>\mathrm{E}$ & 4.29 & 0.051 \\
\hline
\end{tabular}

Abbreviations: $\mathrm{R}=$ right; $\mathrm{E}=$ evening; $\mathrm{M}=$ morning. 


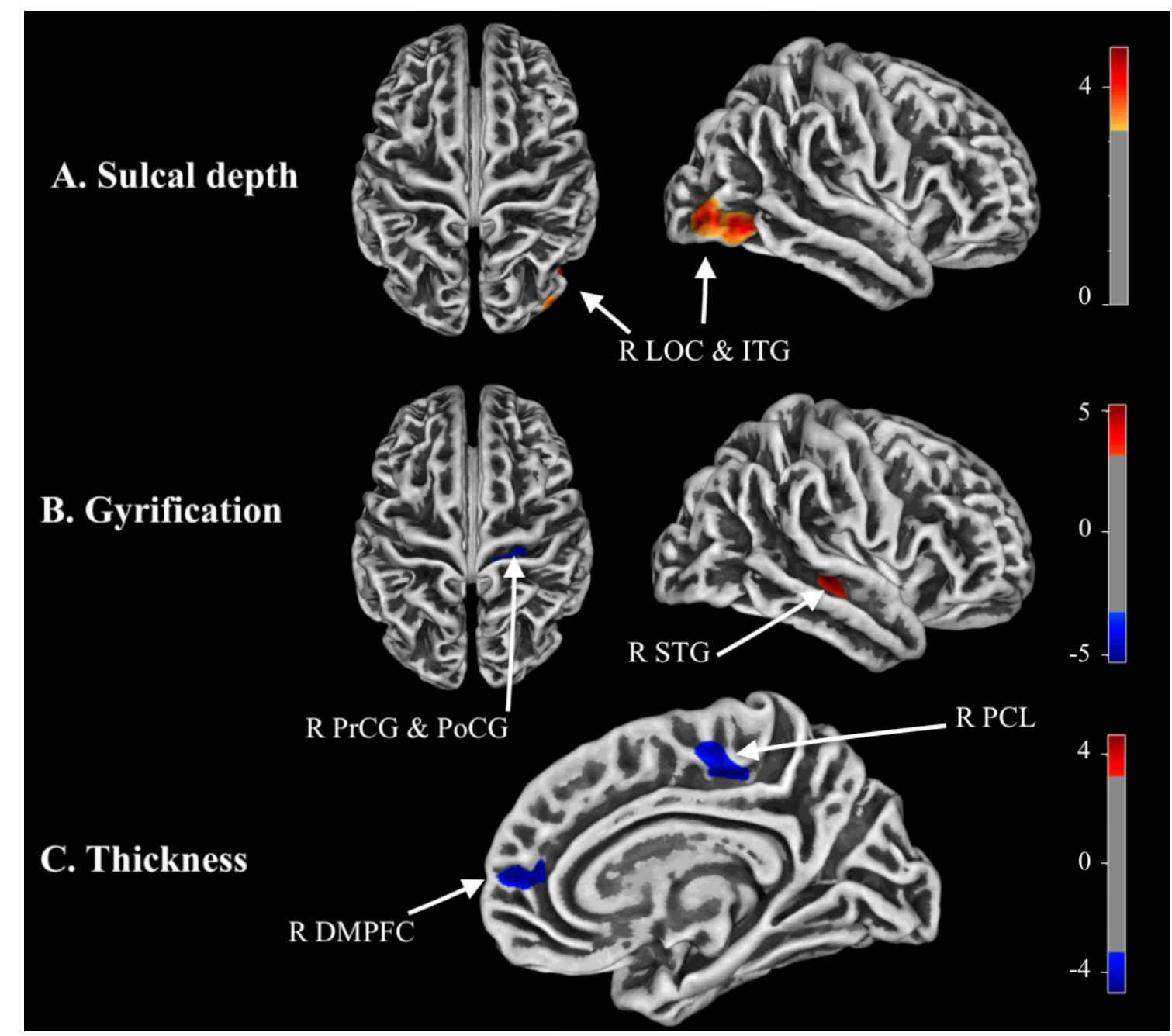

Figure 3. Brain regions with time-of-day (TOD) differences in the cortical surface parameters.

Warm colours indicate increased values from morning to evening, while cold shades stand for decreased metrics from morning to evening. Abbreviations: R, right; LOC, lateral occipital cortex; ITG, inferior temporal gyrus; PrCG, precentral gyrus; PoCG, postcentral gyrus; STG, superior temporal gyrus; DMPFC, dorsomedial prefrontal cortex; PCL, paracentral lobule.

\subsection{Overlap between TOD VBM and SBM results}

Group-level analysis yielded the right inferior temporal gyrus to be a site of increases in both GM volume and sulcal depth. The significant cluster from the VBM analysis was projected onto the cortical surface using AFNI (Cox, 1996) and SUMA (Saad and Reynolds, 2012), and was found to be within the area occupied by the larger sulcal depth cluster from the surface analysis (see Figure 4). As the TOD differences in the variables were not normally distributed (both $\mathrm{p}<0.001$ ), Spearman correlation was applied. The TOD changes in the volumetric and surface parameters were significantly correlated with each other $(\rho=0.39 ; p<0.001$; see Figure 5 for data distribution). 


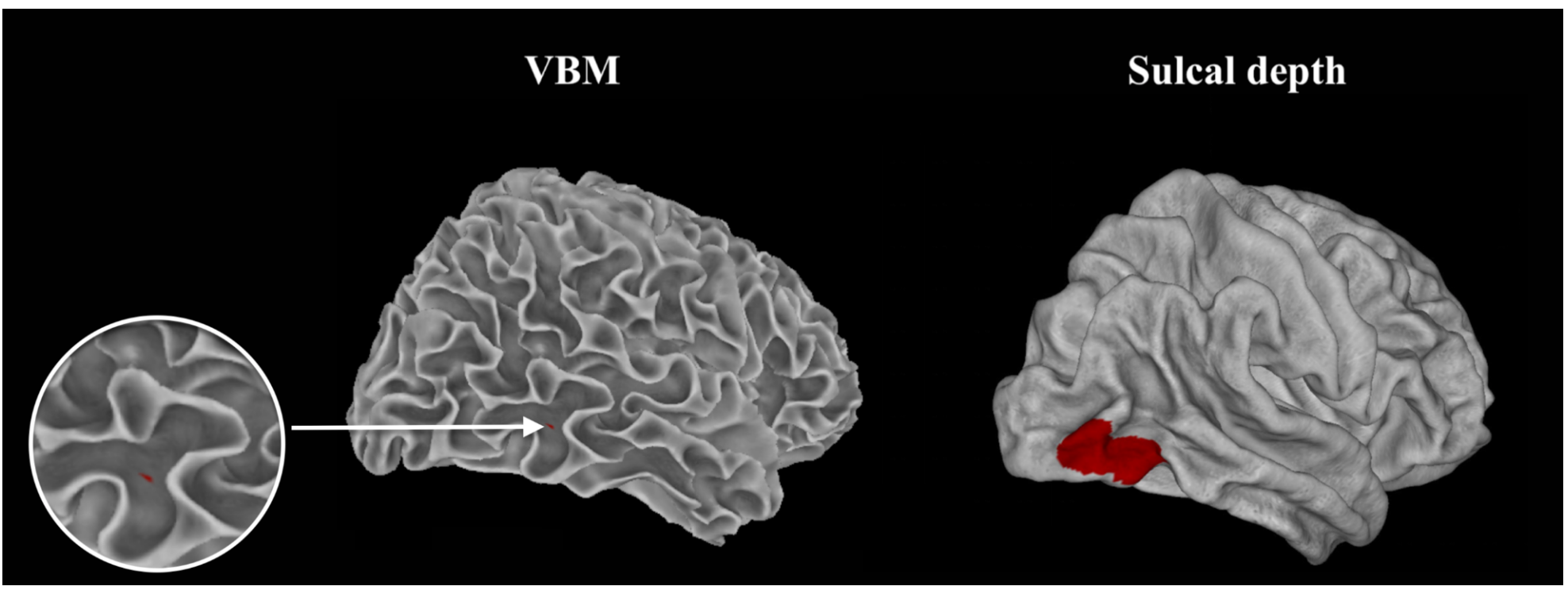

Figure 4. The spatial correspondence between the cluster of increased grey matter (GM) volume (on the left; indicated with an arrow) and the area of increased sulcal depth (on the right) in the right inferior temporal gyrus. The former finding was found to be within the larger area covered by the latter result. Abbreviations: VBM, voxel based morphometry.

$$
\rho=0.39, p<0.001
$$

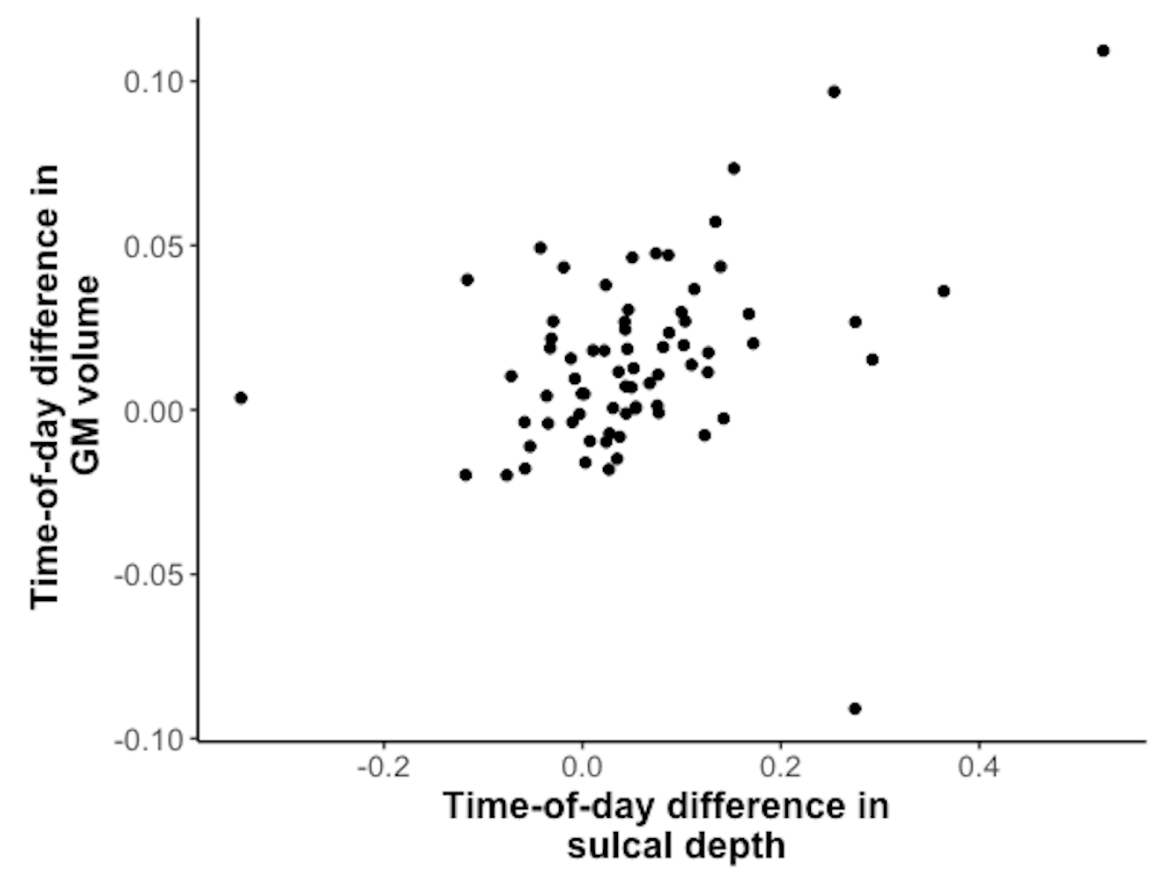

Figure 5. The distribution of the morning-to-evening changes in sulcal depth and grey matter (GM) volume in the right inferior temporal gyrus. The two structural measures were found to be significantly correlated $(\rho=0.39 ; p<0.001)$.

\section{Discussion}




\subsection{The influence of TOD on global anatomical metrics}

Our study found no significant morning-to-evening variation for any of the global metrics. The lack of such differences in the case of sulcal depth and gyrification index is in line with the literature (Trefler et al., 2016), however, other results from this investigation do not fully correspond with the earlier reports. Two previously published longitudinal studies reported significant TOD-related brain volume reductions $(n=1589$, Nakamura et al., 2015; $n=19$, Trefler et al., 2016), while a larger cross-sectional report did not $(n=3279$; Book et al., 2021). Additionally, one study that contained data of one healthy participant and one multiple sclerosis patient from 19 time points detected no consistent TOD variation in the brain volume (Narayanan et al., 2020). Our work is thus the first one to report no TOD fluctuation in brain volume in a longitudinal study on a group-level.

Similarly, earlier longitudinal studies found TOD-related decreases in GM and WM volume, and cortical thickness, as well as a morning-to-evening increase in CSF volume (Trefler et al., 2016; Karch et al., 2019), with no such results stemming from our study. In turn, our finding of a strong inverse correlation between the TOD change in GM and CSF volumes $(\rho=$ $-0.86)$ extends on the previous report by Trefler and colleagues $(r=-0.52$; Trefler et al, 2016). Nevertheless, our investigation did not replicate their finding of a negative association between the change in WM and CSF volumes ( $\rho=0.08$ vs. $r=-0.29$ ), and in contrast with the earlier report we found a moderate relationship between the TOD differences in GM and WM volumes $(\rho=-0.50$ vs. $r=-0.07)$.

To rule out a possibility that the discrepancy in findings is a result of the use of different neuroimaging software, we processed the morning session scans in FreeSurfer (version 5.3; Fischl, 2012) commonly deployed in the referenced papers. The GM and WM volumes calculated by two methods showed excellent correlations (respectively: $r=0.95 ; r=0.99$ ), and cortical thickness comparison yielded reasonable comparability between the methods $(r=0.76)$. The lack of such calculations for the CSF volume stemmed from the fact that the measure is calculated differently in both softwares, i.e. FreeSurfer does not segment sulcal CSF. Thus, it is highly unlikely that the cortical thickness, GM, WM and brain volume findings are strongly affected by the software used, however, this possibility cannot be ruled out for the CSF results.

\subsection{Potential sources of variability in global TOD effects}

Previous studies have reported a considerable extent of variability in the daily TOD effects. In one study with three participants scanned for approximately 40 times across 31 days at different hours of the day, only one showed a TOD-related increase in ventricular CSF volumes (Maclaren et al., 2014). Similarly, the work by Trefler and colleagues stated that the TOD reduction in brain volume was observed in 16 out of the 19 participants (Trefler et al., 
2016). Our study, with the reduction in brain volume seen in 37 out of 72 participants corresponds well with the large variability in the data observed before.

Regarding the mechanisms behind this phenomenon, Naranayan and colleagues (2020) found that the technical variability dominated the changes in brain volume until the volume loss exceeded $0.6-0.7 \%$. The TOD fluctuation in brain volume detected in their study was found to be below that level, similarly to the magnitude of TOD decrease reported by Nakamura and others ( $\mathrm{n}=1589$, from $-0.09 \%$ to $-0.221 \%$ ICV; Nakamura et al., 2015). While the effect sizes reported by Trefler and colleagues are higher than the order of volume loss attributable to the technical aspects ( $-2.289 \%$ of ICV per $24 \mathrm{~h}$; Trefler et al., 2016), it needs to be remembered that this investigation deployed a relatively small sample of 19 individuals and such studies are prone to effect size overestimation.

Interestingly, the most influential of the technical factors was the relative position of the brain in the scanner (Naranayan et al., 2020; Hedges et al., 2021). Even subtle changes in the head orientation can lead to drastic volumetric differences due to partial voluming-affected voxels. For example, if a voxel situated at the GM-CSF border and formerly classified as GM undergoes repositioning so that now it contains less GM and more CSF, it might result in its reclassification to CSF. If the process simultaneously affects a large enough portion of voxels located at the tissue border, it might lead to a misleading conclusion of CSF volume increase. This could explain the fact that Maclaren and colleagues reported the volumes of cerebral WM and several GM structures to have similar levels of variance between scan-reposition-rescan condition and scanning sessions taking place at different hours and days (Maclaren et al., 2014). The only region found to have greater inter-session than scan-reposition-rescan variability was the lateral ventricle, which enlarged with TOD but only in one of three participants. It has been suggested that ventricular volume changes could reflect the hydration status with dehydration causing their enlargement (Nakamura et al., 2015; Gullans and Verbalis, 1993), however, reports have been published both in favour (Dickson et al., 2005; Kempton et al., 2009; Streitbürger et al., 2012) and against this hypothesis (Karch et al., 2019; Meyers et al, 2016). Further investigation into the underlying mechanisms is warranted as it could help us reduce the extent of variability in the results and increase their reproducibility.

\subsection{The influence of TOD on VBM and SBM metrics}

Our study is the first one to simultaneously consider the TOD effect on GM and WM VBM. The analyses showed that TOD was associated with widespread and often bilaterally-symmetric changes in voxel-level GM and WM volume, with the vast majority of clusters showing increases for the former and decreases for the latter measure. An earlier study by Trefler and colleagues (2016) reported diffused VBM GM volume reductions, including areas such as postcentral gyrus, superior parietal lobe and cerebellum, where we found changes 
in the opposite direction, and caudate nucleus, where we similarly report TOD-related reductions.

In contrast with the VBM findings, TOD-related changes in cortical surface parameters were restricted to a relatively few brain regions. To the best of our knowledge, this work is the first one to investigate vertex-level TOD variation of sulcal depth and gyrification index. The TOD fluctuations in these parameters were found within motor, sensory and higher cognitive cortices. Similarly, we also found a statistically significant decrease in the thickness of the right paracentral lobule and a trend level decrease in the thickness of the right DMPFC. The former finding is in line with the results of the previous investigations (Trefler et al., 2016). Trefler and colleagues, who acquired their second dataset on the same day after two hours of controlled rest, additionally reported a thinning of the prefrontal cortex (PFC; Trefler et al., 2016). In contrast with this result, Elvsåshagen and colleagues, who also scanned their participants twice on the same day but enabled them to perform their regular daily activities during the twelve hour break, found that thickness in the aforementioned cortical region increased (Elvsåshagen et al., 2017). It can be speculated that the thickening of PFC in the latter case was a result of the typical activity during the day, which the participants of the study by Trefler et al. were bereft of. The experimental design deployed in the current work most likely reflects a combination of circadian and experience-dependent effects as prior to the evening sessions participants had performed their routine non-strenuous daily activities. Our trend-level finding needs to be treated with caution, nonetheless, it underlines the need for future studies to make a clear distinction between circadian and experience-dependent mechanisms.

Last but not least, the comparison of VBM GM and surface analyses results revealed that the TOD increases in VBM GM and sulcal depth within the right inferior temporal gyrus were moderately correlated $(\rho=0.39$ ), suggesting that in some brain regions the same underlying processes could contribute to both voxel- and surface-based parameters. Nevertheless, the area occupied by the VBM cluster was much smaller than that of the sulcal depth cluster, which might have attenuated the strength of the correlation between these two measures.

\subsection{Potential mechanisms behind the voxel- and vertex-level effects}

While the effects observed at the tissue borders are likely most strongly affected by differences in partial voluming due to changes in head positioning within the scanner, the prevalence of the significant results beyond these areas implicate that a combination of experience- and circadian-dependent processes may also contribute to the observed results, intertwining to produce region-specific effects.

A body of literature has shown that experience-related changes in the structure of the brain are visible within the time frame of hours (Sagi et al., 2012; Hofstetter et al., 2013; Ding et 
al., 2013). These studies often reported decreased mean diffusivity in regions active during the task execution, and in one case linked it with behavioural improvement following the training (Hofstetter et al., 2013). One plausible explanation for the decrease in water diffusivity is the reduction of extracellular space as a result of activity-induced swelling of neurons and glial cells, including astrocytes and oligodendrocytes (Chvatal et al., 1997; Xie et al., 2013; Sagi et al., 2012). Within the same time frame, precursors of oligodendrocytes have been found to proliferate and differentiate into mature cells, increasing the myelin sheath around electrically active axons (Gibson et al., 2014; Xiao et al., 2016). Experience-dependent plasticity also affects dendritic spines of neurons with the initial stages of learning inducing new spine formation (Hübener and Bonhoeffer, 2010). Interestingly, many of the brain structures where we found TOD differences, such as medial temporal lobes, striatum, orbitofrontal cortex, as well as associated fornix and cingulate bundles, belong to neural networks involved in multiple aspects of memory (Squire and Zola-Morgan, 1991; Packard et al., 1989). One fMRI study deploying a comparable experimental design to that of our own found a pronounced morning to evening increase in resting-state functional connectivity between the medial temporal lobes and other brain areas involved in memory functions, similar to those stemming from our study (Shannon et al., 2013). Within that context, our results may be, at least partially, related to memory formation.

On the other hand, dendritic spine formation and elimination is also known to be under circadian control and occur without any environmental stimulation (Ikeno et al., 2014; see Krzeptowski et al., 2018 for a detailed review). Circadian-controlled peaks in glucocorticoid secretion induce postsynaptic dendritic spine formation in the hippocampus (Ikeda et al., 2015), as well as in the mouse cortex after motor skill learning (Liston et al., 2013). Glucocorticoids have also been found to affect plasticity within the motor cortex in humans (Clow et al., 2014). Additionally, in people with stable sleeping routines, the amount of fluid detectable in the perivascular spaces of WM increases with TOD (Barisano et al., 2021). In line with this evidence, mean diffusivity, known to be influenced by perivascular spaces (Sepehrband et al., 2019), grows larger from morning to afternoon in the absence of cognitive training (Thomas et al., 2018).

The processes described above are known to lead to changes detectable in the T1-weighted signal. Increased GM density has been found to positively correlate with neurogenesis in hippocampus, dendritic spine density and physical volume of a predefined group of cells (Keifer et al., 2015; Suzuki et al., 2015; Asan et al., 2021). In turn, as white matter owes its signal intensity on T1-weighted images to myelin content, increase in myelination and perivascular fluid volume should lead to, respectively, increased and decreased voxel-level WM volume. 


\subsection{Implications of the findings}

Our findings indicate that controlling the time of data acquisition is a crucial step that needs to be undertaken at the stage of planning structural neuroimaging research. Poor experimental planning in cross-sectional studies with a bias in the time of scanning between the groups may result in significant distinctions between the groups being reported in the absence of any true effect. In the case of longitudinal studies, the lack of strict data acquisition time control may have its consequences in misattributing the effects of training to the variance associated with TOD. One of the strengths of our work lies in the fact that compared to the previous reports we controlled participants for a stable sleeping routine and no sleep-related disorders, especially that both sleep and sleep deprivation have been reported to influence VBM and cortical thickness (Bernardi et al., 2016; Elvsåshagen et al., 2017; Sun et al., 2020).

Our results show that the TOD variance in structural brain parameters is far more ubiquitous for VBM than SBM. One potential explanation lies in the fact the latter does not base its measurements on signal intensity in voxels per se but rather uses them to derive specific parameters of tissue organisation. For example, if the intensity of voxels within a certain cortical area increases from morning to evening, this might be detected as an increase in GM volume in the VBM analysis. At the same time, the relative distance between the WM-GM and GM-pial borders may not change at all, resulting in the lack of differences in cortical thickness.

Nevertheless, as our study reports significant regional TOD effects for all of the performed surface analyses, we recommend that TOD is uniformly controlled across all kinds of structural neuroimaging research. This could be preferably achieved through scheduling participants' scans to a short time window during the day, or alternatively through balancing the time of data acquisition amongst participants and including TOD as a confounder in the statistical analysis.

\subsection{Limitations}

One limitation of our study lies in the fact that its experimental design does not enable differentiation between circadian- and experience-dependent effects. Nevertheless, it can also be considered one of its major strengths as neuroimaging studies often do not account for time of data acquisition and participants' activity performed on the day of the scan prior to the visit in the laboratory. Thus, our findings constitute a representative of the effects that can be otherwise misattributed to experimental manipulation. Additionally, the CSF results from our investigation could not be validated against the software used in the previous reports due to the distinctions in how the different preprocessing strategies treat sulcal CSF.

\section{Conclusions}


Our study shows that TOD has a prevalent effect on structural brain metrics on the voxel- and vertex- but not global level. We extend the previously published research by showing that both increases and decreases in regional VBM and SBM parameters can be observed. All in all, TOD is a crucial factor to be considered and controlled for at the stage of experimental planning and data analysis.

\section{Funding}

This work was supported by the National Science Centre, Poland (NCN) [grant number 2013/08/M/HS6/00042].

\section{Data availability}

The dataset used in this study will be made available upon manuscript acceptance.

\section{CRediT author statement}

MRZ: Conceptualization, Methodology, Investigation, Formal Analysis, Validation, Data Curation, Writing - Original Draft, Visualization. MF: Conceptualisation, Methodology, Investigation, Data Curation, Writing - Review \& Editing, Funding Acquisition. TM: Conceptualisation, Methodology, Writing - Review \& Editing, Funding Acquisition. EB: Investigation, Formal Analysis, Validation, Writing - Review \& Editing. HO: Investigation, Formal Analysis, Writing - Review \& Editing. AD: Conceptualisation, Methodology, Investigation, Formal Analysis, Validation, Data Curation, Writing - Review \& Editing, Supervision. All authors contributed to the article and approved the submitted version.

\section{Acknowledgements}

This research was supported in part by PL-Grid Infrastructure. We thank Prof. Patricia Reuter-Lorenz for her constructive suggestions during the planning and development of the Harmonia project and her valuable support. We also thank Anna Beres, Piotr Faba, Koryna Lewandowska, Monika Ostrogorska, Barbara Sikora-Wachowicz for their assistance with the fMRI data collection, Aleksandra Zyrkowska for help with the process of participant selection, and Magdalena Debowska for help in collecting actigraphy data.

\section{Declarations of interest}

Authors report no conflict of interests.

\section{References}

Asan L, Falfán-Melgoza C, Beretta CA, Sack M, Zheng L, Weber-Fahr W, Kuner T, Knabbe J. Cellular correlates of gray matter volume changes in magnetic resonance morphometry 
identified by two-photon microscopy. Sci Rep. 2021 Feb 19;11(1):4234. doi: 10.1038/s41598-021-83491-8.

Ashburner, J., Friston, KJ. (2000) Voxel-based morphometry - the methods. Neuroimage 11(6):805-821. https://doi.org/10.1006/nimg.2000.0582

Barisano G, Sheikh-Bahaei N, Law M, Toga AW, Sepehrband F. Body mass index, time of day and genetics affect perivascular spaces in the white matter. J Cereb Blood Flow Metab. 2021 Jul;41(7):1563-1578. doi: 10.1177/0271678X20972856.

Bernardi G, Cecchetti L, Siclari F, Buchmann A, Yu X, Handjaras G, Bellesi M, Ricciardi E, Kecskemeti SR, Riedner BA, Alexander AL, Benca RM, Ghilardi MF, Pietrini P, Cirelli C, Tononi G. Sleep reverts changes in human gray and white matter caused by wake-dependent training. Neuroimage. 2016 Apr 1;129:367-377. doi: 10.1016/j.neuroimage.2016.01.020.

Book GA, Meda SA, Janssen R, Dager AD, Poppe A, Stevens MC, Assaf M, Glahn D, Pearlson GD. Effects of weather and season on human brain volume. PLoS One. 2021 Mar 24;16(3):e0236303. doi: 10.1371/journal.pone.0236303.

Buysse, D. J., Reynolds, C.F. 3rd, Monk, T. H., Berman, S. R., Kupfer, D. J. (1989) The Pittsburgh Sleep Quality Index: a new instrument for psychiatric practice and research. Psychiatry Research 28(2):193-213. https://doi.org/10.1016/0165-1781(89)90047-4

Cardinale F, Chinnici G, Bramerio M, Mai R, Sartori I, Cossu M, Lo Russo G, Castana L, Colombo N, Caborni C, De Momi E, Ferrigno G. Validation of FreeSurfer-estimated brain cortical thickness: comparison with histologic measurements. Neuroinformatics. 2014 Oct;12(4):535-42. doi: 10.1007/s12021-014-9229-2.

Chen, G., Adleman, N. E., Saad, Z. S., Leibenluft, E., Cox, R. W. (2014) Applications of Multivariate Modeling to Neuroimaging Group Analysis: A Comprehensive Alternative to Univariate General Linear Model. Neuroimage 99:571-588. https://doi.org/10.1016/j.neuroimage.2014.06.027

Chvátal A, Berger T, Vorísek I, Orkand RK, Kettenmann H, Syková E. Changes in glial K+ currents with decreased extracellular volume in developing rat white matter. J Neurosci Res. 1997 Jul 1;49(1):98-106. doi: 10.1002/(sici)1097-4547(19970701)49:1<98::aid-jnr11>3.0.co;2-0.

Clow A, Law R, Evans P, Vallence AM, Hodyl NA, Goldsworthy MR, Rothwell JR, Ridding MC. Day differences in the cortisol awakening response predict day differences in synaptic plasticity in the brain. Stress. 2014 May;17(3):219-23. doi: 10.3109/10253890.2014.905533.

Cox, R. W. (1996) AFNI: software for analysis and visualization of functional magnetic resonance neuroimages. Computers and Biomedical Research 29(3):162-173. https://doi.org/10.1006/cbmr.1996.0014

Dahnke R, Yotter RA, Gaser C. Cortical thickness and central surface estimation. Neuroimage. 2013 Jan 15;65:336-48. 
Dickson JM, Weavers HM, Mitchell N, Winter EM, Wilkinson ID, Van Beek EJ, Wild JM, Griffiths PD. The effects of dehydration on brain volume -- preliminary results. Int J Sports Med. 2005 Jul-Aug;26(6):481-5. doi: 10.1055/s-2004-821318.

Ding AY, Li Q, Zhou IY, Ma SJ, Tong G, McAlonan GM, Wu EX. MR diffusion tensor imaging detects rapid microstructural changes in amygdala and hippocampus following fear conditioning in mice. PLoS One. 2013;8(1):e51704. doi: 10.1371/journal.pone.0051704.

Elvsåshagen T, Zak N, Norbom LB, Pedersen PØ, Quraishi SH, Bjørnerud A, Alnæs D, Doan NT, Malt UF, Groote IR, Westlye LT. Evidence for cortical structural plasticity in humans after a day of waking and sleep deprivation. Neuroimage. 2017 Aug 1;156:214-223. doi: 10.1016/j.neuroimage.2017.05.027.

Fafrowicz M, Bohaterewicz B, Ceglarek A, Cichocka M, Lewandowska K, Sikora-Wachowicz B, Oginska H, Beres A, Olszewska J, Marek T. Beyond the Low Frequency Fluctuations: Morning and Evening Differences in Human Brain. Front Hum Neurosci. 2019 Aug 27;13:288. doi: 10.3389/fnhum.2019.00288.

Farahani FV, Fafrowicz M, Karwowski W, Bohaterewicz B, Sobczak AM, Ceglarek A, Zyrkowska A, Ostrogorska M, Sikora-Wachowicz B, Lewandowska K, Oginska H, Beres A, Hubalewska-Mazgaj M, Marek T. Identifying Diurnal Variability of Brain Connectivity Patterns Using Graph Theory. Brain Sci. 2021 Jan 16;11(1):111. doi: 10.3390/brainsci11010111.

Fischl B. FreeSurfer. Neuroimage. 2012 Aug 15;62(2):774-81. doi: 10.1016/j.neuroimage.2012.01.021

Gaser, C., Dahnke, R. (2016) CAT - A Computational Anatomy Toolbox for the Analysis of Structural MRI Data. OHBM Annual Meeting. 2016; 336-348.

Gibson EM, Purger D, Mount CW, Goldstein AK, Lin GL, Wood LS, Inema I, Miller SE, Bieri G, Zuchero JB, Barres BA, Woo PJ, Vogel H, Monje M. Neuronal activity promotes oligodendrogenesis and adaptive myelination in the mammalian brain. Science. 2014 May 2;344(6183):1252304. doi: 10.1126/science.1252304.

Gullans SR, Verbalis JG. Control of brain volume during hyperosmolar and hypoosmolar conditions. Annu Rev Med. 1993;44:289-301. doi: 10.1146/annurev.me.44.020193.001445.

Han X, Jovicich J, Salat D, van der Kouwe A, Quinn B, Czanner S, Busa E, Pacheco J, Albert M, Killiany R, Maguire P, Rosas D, Makris N, Dale A, Dickerson B, Fischl B. Reliability of MRI-derived measurements of human cerebral cortical thickness: the effects of field strength, scanner upgrade and manufacturer. Neuroimage. 2006 Aug 1;32(1):180-94. doi: 10.1016/j.neuroimage.2006.02.05

Hedges EP, Dimitrov M, Zahid U, Brito Vega B, Si S, Dickson H, McGuire P, Williams S, Barker GJ, Kempton MJ. Reliability of structural MRI measurements: The effects of scan session, head tilt, inter-scan interval, acquisition sequence, FreeSurfer version and processing stream. Neuroimage. 2021 Nov 27;246:118751. doi: 10.1016/j.neuroimage.2021.118751 
Hofstetter S, Tavor I, Tzur Moryosef S, Assaf Y. Short-term learning induces white matter plasticity in the fornix. J Neurosci. 2013 Jul 31;33(31):12844-50. doi: 10.1523/JNEUROSCI.4520-12.2013.

Hübener M, Bonhoeffer T. Searching for engrams. Neuron. 2010 Aug 12;67(3):363-71. doi: 10.1016/j.neuron.2010.06.033.

Ikeda M, Hojo Y, Komatsuzaki Y, Okamoto M, Kato A, Takeda T, Kawato S. Hippocampal spine changes across the sleep-wake cycle: corticosterone and kinases. J Endocrinol. 2015 Aug;226(2):M13-27. doi: 10.1530/JOE-15-0078.

Ikeno T, Weil ZM, Nelson RJ. Timing of light pulses and photoperiod on the diurnal rhythm of hippocampal neuronal morphology of Siberian hamsters. Neuroscience. 2014 Jun 13;270:69-75. doi: 10.1016/j.neuroscience.2014.04.002.

Johns, M. W. (1991) A new method for measuring daytime sleepiness: the Epworth sleepiness scale. Sleep 14(6):540-5. https://doi.org/10.1093/sleep/14.6.540

Karch JD, Filevich E, Wenger E, Lisofsky N, Becker M, Butler O, Mårtensson J, Lindenberger U, Brandmaier AM, Kühn S. Identifying predictors of within-person variance in MRI-based brain volume estimates. Neuroimage. 2019 Oct 15;200:575-589. doi: 10.1016/j.neuroimage.2019.05.030.

Keifer OP Jr, Hurt RC, Gutman DA, Keilholz SD, Gourley SL, Ressler KJ. Voxel-based morphometry predicts shifts in dendritic spine density and morphology with auditory fear conditioning. Nat Commun. 2015 Jul 7;6:7582. doi: 10.1038/ncomms8582.

Kempton MJ, Ettinger U, Schmechtig A, Winter EM, Smith L, McMorris T, Wilkinson ID, Williams SC, Smith MS. Effects of acute dehydration on brain morphology in healthy humans. Hum Brain Mapp. 2009 Jan;30(1):291-8. doi: 10.1002/hbm.20500.

Krzeptowski W, Hess G, Pyza E. Circadian Plasticity in the Brain of Insects and Rodents. Front Neural Circuits. 2018 May 2;12:32. doi: 10.3389/fncir.2018.00032.

Liston C, Cichon JM, Jeanneteau F, Jia Z, Chao MV, Gan WB. Circadian glucocorticoid oscillations promote learning-dependent synapse formation and maintenance. Nat Neurosci. 2013 Jun;16(6):698-705. doi: 10.1038/nn.3387.

Luders E, Thompson PM, Narr KL, Toga AW, Jancke L, Gaser C. A curvature-based approach to estimate local gyrification on the cortical surface. Neuroimage. 2006 Feb 15;29(4):1224-30.

Maclaren J, Han Z, Vos SB, Fischbein N, Bammer R. Reliability of brain volume measurements: a test-retest dataset. Sci Data. 2014 Oct 14;1:140037. doi: 10.1038/sdata.2014.37.

Marek T, Fafrowicz M, Golonka K, Mojsa-Kaja J, Oginska H, Tucholska K, Urbanik A, Beldzik E, Domagalik A. Diurnal patterns of activity of the orienting and executive attention neuronal networks in subjects performing a Stroop-like task: a functional magnetic resonance imaging study. Chronobiol Int. 2010 Jul;27(5):945-58. doi: 10.3109/07420528.2010.489400. 
Meyers SM, Tam R, Lee JS, Kolind SH, Vavasour IM, Mackie E, Zhao Y, Laule C, Mädler B, Li DK, MacKay AL, Traboulsee AL. Does hydration status affect MRI measures of brain volume or water content? J Magn Reson Imaging. 2016 Aug;44(2):296-304. doi: 10.1002/jmri.25168.

Nakamura K, Brown RA, Narayanan S, Collins DL, Arnold DL; Alzheimer's Disease Neuroimaging Initiative. Diurnal fluctuations in brain volume: Statistical analyses of MRI from large populations. Neuroimage. 2015 Sep;118:126-32. doi: 10.1016/j.neuroimage.2015.05.077. Narayanan S, Nakamura K, Fonov VS, Maranzano J, Caramanos Z, Giacomini PS, Collins DL, Arnold DL. Brain volume loss in individuals over time: Source of variance and limits of detectability. Neuroimage. 2020 Jul 1;214:116737. doi: 10.1016/j.neuroimage.2020.116737.

Oginska, H. (2011) Can you feel the rhythm? A short questionnaire to describe two dimensions of chronotype. Personality and Individual Differences 50(7):1039-1043. https://doi.org/10.1016/j.paid.2011.01.020

Oginska, H., Mojsa-Kaja, J., Mairesse, O. (2017) Chronotype description: In search of a solid subjective amplitude scale. Chronobiology International 34(10):1388-1400. https://doi.org/10.1080/07420528.2017.1372469

Orban C, Kong R, Li J, Chee MWL, Yeo BTT. Time of day is associated with paradoxical reductions in global signal fluctuation and functional connectivity. PLoS Biol. 2020 Feb 18;18(2):e3000602. doi: 10.1371/journal.pbio.3000602.

Packard MG, Hirsh R, White NM. Differential effects of fornix and caudate nucleus lesions on two radial maze tasks: evidence for multiple memory systems. J Neurosci. 1989 May;9(5):1465-72. doi: 10.1523/JNEUROSCI.09-05-01465.1989.

R.A. Yotter, R. Dahnke, P.M. Thompson, C. Gaser (2011): Topological Correction of Brain Surface Meshes Using Spherical Harmonics. Human Brain Mapping, 32(7): 1109-24

Radua J, Vieta E, Shinohara R, Kochunov P, Quidé Y, Green MJ, Weickert CS, Weickert T, Bruggemann J, Kircher T, Nenadić I, Cairns MJ, Seal M, Schall U, Henskens F, Fullerton JM, Mowry B, Pantelis C, Lenroot R, Cropley V, Loughland C, Scott R, Wolf D, Satterthwaite TD, Tan Y, Sim K, Piras F, Spalletta G, Banaj N, Pomarol-Clotet E, Solanes A, Albajes-Eizagirre A, Canales-Rodríguez EJ, Sarro S, Di Giorgio A, Bertolino A, Stäblein M, Oertel V, Knöchel C, Borgwardt S, du Plessis S, Yun JY, Kwon JS, Dannlowski U, Hahn T, Grotegerd D, Alloza C, Arango C, Janssen J, Díaz-Caneja C, Jiang W, Calhoun V, Ehrlich S, Yang K, Cascella NG, Takayanagi Y, Sawa A, Tomyshev A, Lebedeva I, Kaleda V, Kirschner M, Hoschl C, Tomecek D, Skoch A, van Amelsvoort T, Bakker G, James A, Preda A, Weideman A, Stein DJ, Howells F, Uhlmann A, Temmingh H, López-Jaramillo C, Díaz-Zuluaga A, Fortea L, Martinez-Heras E, Solana E, Llufriu S, Jahanshad N, Thompson P, Turner J, van Erp T; ENIGMA Consortium collaborators. Increased power by harmonizing structural MRI site differences with the ComBat 
batch adjustment method in ENIGMA. Neuroimage. 2020 Sep;218:116956. doi: 10.1016/j.neuroimage.2020.116956.

Saad, Z. S., Reynolds, R. C. (2012) SUMA. Neuroimage 62:768-773. https://doi.org/10.1016/j.neuroimage.2011.09.016

Sagi Y, Tavor I, Hofstetter S, Tzur-Moryosef S, Blumenfeld-Katzir T, Assaf Y. Learning in the fast lane: new insights into neuroplasticity. Neuron. 2012 Mar 22;73(6):1195-203. doi: 10.1016/j.neuron.2012.01.025.

Sepehrband F, Cabeen RP, Choupan J, Barisano G, Law M, Toga AW; Alzheimer's Disease Neuroimaging Initiative. Perivascular space fluid contributes to diffusion tensor imaging changes in white matter. Neuroimage. 2019 Aug 15;197:243-254. doi: 10.1016/j.neuroimage.2019.04.070.

Shannon BJ, Dosenbach RA, Su Y, Vlassenko AG, Larson-Prior LJ, Nolan TS, Snyder AZ, Raichle ME. Morning-evening variation in human brain metabolism and memory circuits. $\mathrm{J}$ Neurophysiol. 2013 Mar;109(5):1444-56. doi: 10.1152/jn.00651.2012.

Squire LR, Zola-Morgan S. The medial temporal lobe memory system. Science. 1991 Sep 20;253(5026):1380-6. doi: 10.1126/science.1896849.

Streitbürger DP, Möller HE, Tittgemeyer M, Hund-Georgiadis M, Schroeter ML, Mueller K. Investigating structural brain changes of dehydration using voxel-based morphometry. PLoS One. 2012;7(8):e44195. doi: 10.1371/journal.pone.0044195.

Sun J, Zhao R, Yang X, Deng H, Zhu Y, Chen Y, Yuan K, Xi Y, Yin H, Qin W. Alteration of Brain Gray Matter Density After 24 h of Sleep Deprivation in Healthy Adults. Front Neurosci. 2020 Aug 11;14:754. doi: 10.3389/fnins.2020.00754.

Suzuki H, Sumiyoshi A, Matsumoto Y, Duffy BA, Yoshikawa T, Lythgoe MF, Yanai K, Taki Y, Kawashima R, Shimokawa H. Structural abnormality of the hippocampus associated with depressive symptoms in heart failure rats. Neuroimage. 2015 Jan 15;105:84-92. doi: 10.1016/j.neuroimage.2014.10.040.

Thomas C, Sadeghi N, Nayak A, Trefler A, Sarlls J, Baker CI, Pierpaoli C. Impact of time-of-day on diffusivity measures of brain tissue derived from diffusion tensor imaging. Neuroimage. 2018 Jun;173:25-34. doi: 10.1016/j.neuroimage.2018.02.026.

Trefler A, Sadeghi N, Thomas AG, Pierpaoli C, Baker CI, Thomas C. Impact of time-of-day on brain morphometric measures derived from $\mathrm{T} 1$-weighted magnetic resonance imaging. Neuroimage. 2016 Jun;133:41-52. doi: 10.1016/j.neuroimage.2016.02.034.

Voldsbekk I, Maximov II, Zak N, Roelfs D, Geier O, Due-Tønnessen P, Elvsåshagen T, Strømstad M, Bjørnerud A, Groote I. Evidence for wakefulness-related changes to extracellular space in human brain white matter from diffusion-weighted MRI. Neuroimage. 2020 May 15;212:116682. doi: 10.1016/j.neuroimage.2020.116682. 
Xiao L, Ohayon D, McKenzie IA, Sinclair-Wilson A, Wright JL, Fudge AD, Emery B, Li H, Richardson WD. Rapid production of new oligodendrocytes is required in the earliest stages of motor-skill learning. Nat Neurosci. 2016 Sep;19(9):1210-1217. doi: 10.1038/nn.4351.

Xie L, Kang H, Xu Q, Chen MJ, Liao Y, Thiyagarajan M, O'Donnell J, Christensen DJ, Nicholson C, Iliff JJ, Takano T, Deane R, Nedergaard M. Sleep drives metabolite clearance from the adult brain. Science. 2013 Oct 18;342(6156):373-7. doi: 10.1126/science.1241224.

Zareba, M. R., Fafrowicz, M., Marek, T., Beldzik, E., Oginska, H., Domagalik, A. (2021) Late chronotype is linked to greater cortical thickness in the left fusiform and entorhinal gyri. Biological Rhythm Research. doi: 10.1080/09291016.2021.1990501. 